\title{
Feasibility: Individual and Collective ${ }^{1}$
}

\section{Zofia Stemplowska}

Since there is so much we can do together - good and bad - we are subject to numerous normative requirements to perform certain actions and to abstain from others. In what follows I will argue that some intuitively feasible requirements, especially those that are collective, are not in fact feasible. I thereby aim to offer a revised account of what counts as a feasible action. In particular, I argue that we can best preserve the spirit of what is known as the conditional account of feasibility if we move to what I call the constrained account. ${ }^{2}$

What is at stake in offering an account of feasibility is twofold. First, we gain conceptual intuitiveness - it's better if the concepts we use seem intuitively right to us. Second, our account of feasibility has implications for the content of our normative requirements. This is so if, as many do, we accept that 'ought' implies 'is feasible'. But it is also the case even if we reject it, just as long as we agree, as I think we should, that feasibility bears on the content or the status of what is required. ${ }^{3}$

\section{What is feasibility?}

What counts as a feasible action? ${ }^{4}$ It might be tempting to see feasibility simply as a function of possibility and/or the likelihood of success of an agent performing the action. But any such account is subject to a powerful counterexample, most memorably illustrated by Estlund's chicken dance case. ${ }^{5}$ Suppose that there is nothing that anyone could do to induce me to dance like a chicken in front of my students (as it happens, a high enough monetary reward would do the trick, but, suppose, it would not). It is thus extremely unlikely, indeed, close to impossible, that I will so 
dance. Surely, however, we should think that it is, nonetheless, feasible for me to dance like a chicken. The possibility/likelihood account then delivers the counterintuive answer here.

The conditional account of feasibility, by contrast, deals with such cases by stipulating that feasibility - roughly put for now - is a function of the possibility and/or likelihood of success of an agent performing an action, conditional on trying. Depending on whose formulation we follow, an action is feasible if it is possible ${ }^{6}$ or if it is reasonably probable ${ }^{7}$ conditional on trying and the more likely it is, conditional on trying, the more feasible it is. Thus Brennan and Southwood define feasibility as 'reasonable probability of success conditional upon trying'. ${ }^{8}$ Gilabert and Lawford-Smith adopt a 'binary test' for what is feasible and a 'scalar test' for what's more or less feasible once we are in the domain of what's feasible delineated by their binary test. They distinguish between hard constraints - i.e. constraints that it would be impossible to overcome, and soft constraints - i.e. constraints that are malleable. According to the binary test, 'it is feasible for $\mathrm{X}$ to $\varphi$ to bring about $\mathrm{O}$ in context $\mathrm{Z}$ only if $\mathrm{X}$ 's $\varphi$-ing to bring about $\mathrm{O}$ is not incompatible with any hard constraints'. According to the scalar test, 'it is more feasible for X to bring about $\mathrm{O}_{1}$ than for $\mathrm{Y}$ to bring about $\mathrm{O}_{2}$ when it is more probable, given soft constraints, for $\mathrm{X}$ to bring about $\mathrm{O}_{1}$ given that he or she tries, than it is for $\mathrm{Y}$ to bring about $\mathrm{O}_{2}$ given that he or she tries'. ${ }^{9}$

We have a number of elements here, which it will be useful to fix for later use (and which are all offered as a list at the end of the article). Let me simplify 'action $\Phi$ is feasible for agent $X$ ' as 'action $\Phi$ is feasible'. I use 'doing $\Phi$ ', ' $\Phi$-ing', 'performing $\Phi$ ' and, if emphasis is needed, 'succeeding in doing $\Phi$ ' interchangeably. Let me also define 'agent $X$ does action $\Phi$ ' as 'in context $\mathrm{C}$ at time $\mathrm{T}$, agent $\mathrm{X}$ succeeds in performing action $\Phi$ thereby bringing about state of affairs S'. Thus, an action $\Phi$ is always defined with reference to the state of affairs $S$ it brings about. An agent may thus succeed in performing $\Phi_{1}$ that brings about $S_{1}$ while also failing at the same time to perform $\Phi_{2}$ that brings about $S_{2}$ (e.g. 'writing a long novel' vs. writing a gripping novel; 'giving CPR' vs. 'saving a life'). The conditional account implies that an agent may fail to 
do an action either because she does not try (and the account finds such failures irrelevant to the calculus of feasibility) or because something intervenes, so to speak, between the trying and the bringing about of the state of affairs S (i.e. the action may be difficult the way building a long bridge is). I assume throughout that 'trying' involves an appropriately sustained attempt so that any failure here is not due to the agent giving up too early. ${ }^{10}$ Finally, the agent $\mathrm{X}$ in question can be a collective agent. By collective agent $\mathrm{X}$, I mean all those individuals $\mathrm{X}_{1} \ldots \mathrm{X}_{\mathrm{n}}$ whose each respective doing of $\Phi_{1} \ldots \Phi_{\mathrm{n}}$ constitutes the collective action $\Phi$.

The conditional account can thus be restated as:

Proposal 1 (the possibility version): Action $\Phi$ is feasible (and more feasible) if it is possible (and more likely ${ }^{11}$ ) for agent $\mathrm{X}$ to $\Phi$ given that $\mathrm{X}$ tries to $\Phi$.

Proposal 2 (the likelihood version): Action $\Phi$ is (more) feasible if agent $\mathrm{X}$ is (more) likely to $\Phi$ given that $\mathrm{X}$ tries to $\Phi$.

The difference between the versions will not matter to me here but let me state for the record that I favour Proposal 2. We have good reason to resist branding as feasible actions whose performance is merely possible (if tried), however unlikely such performance. ${ }^{12}$ In this I follow Brennan and Southwood and adapt their compelling example. ${ }^{13}$ Fixing your heart in open heart surgery is possible for me - by accident, of course, if I and you are extraordinarily lucky - but it's not a feasible course of action for me when you are having a heart attack in my house. I will come back to what might explain our intuitions that such an action is not feasible. For now, let me manage expectations by explaining that I do not plan to resolve here the issue of how likely the success needs to be for the action to count as feasible. For the simplicity of grammatical phrasing it affords, I refer to the success of such actions as 'likely' rather than 'of a certain degree of probability' and I will assume in what follows that the probability of success has to be at last $50 \%$. That said, this is not where my battle lies and I am open to the possibility that it may have to be lower or higher than that. 
The conditional clause of the conditional account neatly deals with the chicken dance case: the likelihood that you will dance like a chicken is very high conditional on trying - if you try, it is an easy thing to do. However, the use of the conditional clause gives rise to two further problems. First, in its zeal not to undercount feasible actions for unmotivated chicken dancers it seems to overcount them for those who are genuinely unable to motivate themselves to carry them out. This is the problem of how to deal with instances of motivational failure.

Second, it does not seem to give the right answer in some cases of collective action. To see this second problem, consider two broad types of collective action. The first type requires coordination, in the sense that what a given individual needs to do depends on what other individuals do. Playing football - at least successfully - is an example of a collective action that requires coordination: whether I kick the ball forward or backward depends on where else my teammates are on the pitch. I will refer to such actions as coordinated if the mechanisms of coordination are in place (e.g. a football team exists, has a manager, etc.) and as uncoordinated if coordination is needed but the mechanisms are absent. The second type of collective action merely has a number of individuals joining in, but what each individual needs to do does not depend - is not responsive to - what the others do. ${ }^{14}$ Erasing the right foot of the St Peter statue in the St Peter's Basilica by repeated touching of it, is an example of what we might call joint collective action: many people simply need to touch the foot (no one, I assume, could, as it were, do it single-handedly).

The problem with the conditional account of feasibility - as it is stated above - is that it suggests that that a joint collective action is more feasible than a coordinated collective action even in cases when the opposite seems intuitively true. For instance, take the joint collective action of everyone on the planet, who has the capacity, touching his or her own nose next Tuesday. Were everyone to try, they would likely succeed (since it is such an easy action for any individual who has the 
capacity). Thus, if feasibility tracks the likelihood of success conditional on trying then this is a feasible action. ${ }^{15}$ But it seems odd to think that an action requiring everyone to touch their own noses is feasible, let alone highly so. It is also odd to think that such an action is more feasible than the coordinated collective action of, say, executing a goal scoring plan in a game of football but, again, this is suggested by the understanding outlined above since the likelihood of executing the plan in the game of football, conditional on trying, will still depend on skill and luck, making it less feasible. More generally, the conditional account suggests that for any action that, if tried, is bound to be successful (e.g. the action of thinking of a bat) it is just as feasible for 3 billion people to perform it as it is for 3 people to perform it. It suggests, implausibly, that we should, say, select the policy of everyone alive, who can, treating each other with kindness, rather than the policy of reforming the UN peace keeping force as a way of securing world peace.

This leaves us with a dilemma. If feasibility is not conditional on trying, then it seems that it is not feasible for people to do all sorts of easy things simply because they do not want to, dancing like a chicken being one of those. But if feasibility is conditional on trying, then all sorts of collective actions implausibly become feasible and our concept of feasibility recommends the wrong type of policy selection. Below I suggest how to avoid the dilemma. In section 2, I focus on the problem of motivation and in section 3 on the problem of collective doing.

\section{The feasibility of unmotivated action}

The rationale for adding the conditional clause to any account of feasibility is, obviously, that merely lacking the motivation to act seems insufficient to signal that the agent lacks the ability to perform the action and thus that the action is not feasible. This is captured so well by the chicken dance objection. For the sake of exposition, let me assume that acting only happens if an agent is motivated to act and let me call all instances in which the agent is not motivated to act as instances of motivational failure. Then the simplest and probably most natural way to understand cases 
when motivational failure does not seem to rule out feasibility is that the agent could make herself appropriately motivated - i.e. she sufficiently controls her motivational states. We can thus describe such cases as ones in which the agent is merely unwilling to do $\Phi$, but motivationally able to. ${ }^{16}$

Many of us also worry, however, that some instances of motivational failure are not instances of mere unwillingness to do $\Phi$, but of what we might call genuine motivational inability: the agent cannot will the action. This inability can manifest itself either in the agent's trying being somehow faulty or in her not even being able to bring herself to try. Typical examples of such genuine motivational inability are thought to include ‘clinical’ cases, such as phobias, addiction, compulsion - all psychological mechanisms that in the philosophical literature, rightly or wrongly (usually wrongly), are assumed to override the agent's will, replacing it with something alien to her. The thought here is that some cases of motivational failure are on a par with situations in which an agent fails to perform action $\Phi$ because, say (to indulge in an illustrative biological fiction), a nail in her head makes it impossible for the right synapses to fire in a way that would allow the agent to be motivated to do $\Phi$. Possibly the most common case about which it is hard to resist the conclusion that we are in the presence of a genuine motivational inability, rather than mere unwillingness, is willing to stay awake despite utter exhaustion. ${ }^{17}$

Contrary to Gilabert and Lawford-Smith, then, trying is not 'something that people can always do' ${ }^{18}$ The difficulty, therefore, becomes to distinguish between cases of mere unwillingness (which do not block feasibility) and cases of genuine motivational inability (which do). It would not help to stipulate that we are interested only in non-clinical cases when discussing feasibility of action. Such a move merely pushes the question of how to distinguish between cases of mere unwillingness and genuine motivational inability one step back. This is because the move either begs the question - we exclude the clinical cases so that we can simply assume, without a good reason, that all remaining cases are cases of mere unwillingness - or, alternatively, the move simply removes some cases from deliberation without, however, settling the issue of how to 
distinguish between mere unwillingness and genuine motivational inability for the remaining cases. ${ }^{19}$

There are numerous attempts to draw the distinction in question. Wiens, for example, has recently argued against Estlund that motivational failure in the presence of a 'good faith' attempt to do $\Phi$ should be seen as an instance of what I called genuine motivational inability that blocks the agent's ability to do $\Phi$ rather than as an instance of mere unwillingness that does not block her ability to do $\Phi$ (with further consequences for what it might be appropriate to require of agents who fail at such good faith attempts). ${ }^{20}$ Without even attempting to do justice to Wiens's perceptive analysis, let me offer a general reason why I think we can be sceptical that the strategy will work for my question here. What counts as a good faith attempt could be defined internally (it appears so to the agent who is making it) and/or externally with reference to conduct (she has made a certain number of sacrifices, etc.). ${ }^{21}$ The problem with an internal definition is that it falls prey to the possibility of self-deception: the agent may be merely unwilling but self-deceiving herself that her attempt is genuine (think of someone who might be 'struggling' against indulging in pleasant temptations). The problem with an external definition, in turn, is that it always makes sense to ask of any externally defined criterion: 'but what if despite the sacrifices, etc., she is really just unwilling to do $\Phi$ ?'. An external definition of motivational (as opposed to some other) failure simply cannot block the possibility - since it cannot point to anything beyond the observable conduct - that had the agent really tried, she would have done it: 'If she really tried to be faithful, she would be'.

Ultimately, instead of reviewing the full range of possibilities for how to draw the distinction on offer, let me make two points. First, I think it is not unreasonable to hold that the issue could only be settled, if at all, through or in conjunction with future empirical work. That is, if it is the case that some motivational failure is an instance of genuine inability and some is not, then it is possible that only complex neurological data (or equivalent) could help settle the issue. Second, however, since we do not have the data, here is a working proposal of my own. Motivational 
failure is an instance of mere unwillingness when there exists a conceivable incentive that would bring the agent's motivational state in line with what is needed to perform the action in question. The incentive exists, on this view, if it would have such a power whether in fact the incentive could be offered in our world. Thus the incentive of 'eternal beauty' or 'immortality' would count on this view. The working proposal, then, defines feasible action as follows:

Proposal 3: Action $\Phi$ is (more) feasible if there is an incentive I such that, given I, X will try to do $\Phi$ and, given I, is (more) likely to do $\Phi$.

This proposal replaces the conditional clause with the existential clause about incentives: if the agent is responsive to incentives then she is not subject to genuine motivational inability. (Whether the action is feasible further depends, on this account, on other obstacles that might block the performance of $\Phi$.) For most people, this makes chicken dancing feasible while competent open heart surgery unfeasible since the typical person would likely succeed in doing the former but not the latter. Numerous instances of motivational failure, including many 'clinical' cases, will now count as instances of mere unwillingness, with corresponding conclusions about their feasibility. I will shortly address the objection that this overestimates the feasibility of actions and a further complication that it underestimates it. First, however, let me point out that the proposal still allows for the existence of genuine motivational inability. For example, usually there comes a point prior to death from exhaustion when even the promise of a world will not suffice for a person to motivate herself to stay awake.

Proposal 3, however, offers only a sufficient condition for feasibility. For, hopefully, there is no incentive, for example, that could make you murder anyone but this does not mean, depending on other features of the case, that the action is not feasible for you. A fuller account of motivational ability, then, should ask not only whether an agent is responsive to any incentives but also about the reasons why she may not be. If her failure to respond is solely due to her seeing action $\Phi$ as (normatively) wrong, then we should not brand her as genuinely motivationally unable. This should be understood counterfactually such that were the agent not to see the action as wrong, she 
would be responsive to incentives. ${ }^{22}$ The category of wrongness here is meant to include moral wrongs as well as ethical wrongs (for those who distinguish between them). Given this, actions such as abstaining from killing but also such as declining to switch religions or worshiping trees remain feasible (assuming no other obstacles) even if they are never attempted on account of one's moral and ethical convictions. By contrast, an action that the agent has no normative objection to, but doing it terrifies her to such an extent that there is no incentive powerful enough to induce her to do it, qualifies as unfeasible. This strikes me as correct: phobias constrain what people are able to do while normative beliefs express who people are rather than constrain them. Revised the proposal becomes:

Proposal 4: Action $\Phi$ is (more) feasible if there is an incentive I - or had the agent X not seen $\Phi$ as wrong there would be I - such that, given I, X will try to $\Phi$ and, given I, X is (more) likely to $\Phi .^{23}$

Let me, then, return to the objection flagged up above that the proposal overidentifies actions as feasible due to it tracking people’s sensitivity to conceivable rather than actual incentives. For example, suppose, that under normal circumstances, I cannot make myself approach a spider but if my child's happiness were at stake, I would. We may worry, then, that, under normal circumstances I am genuinely motivationally unable to approach the spider even if I would be able to do it in other circumstances. But I think, instead, that the incentives test correctly reveals whether an agent would be able to will the action if its payoffs were different, in which case her unwillingness to will it under normal circumstances is not an instance of genuine motivational failure, it is an upshot of her assessment that the effort, so to speak, is not worth the payoff. This point can be restated in terms of a distinction used by G.A. Cohen. ${ }^{24}$ An action can be assessed along two dimensions: its difficulty (with impossibility at one end of the continuum) and its costliness. Taking you on a bicycle to Heathrow from Oxford is difficult but (if I like you) not costly. Kissing a frog is not difficult but is costly (I would experience disgust). A view of feasibility that made feasibility depend on how an agent experiences the action would track its 
costliness. But, as my incentives idea suggests, we should avoid the conclusion that a very costly action is not feasible; if changing the costs means we can will ourselves to perform the action then we reveal the motivational failure as a case of mere unwillingness and we should have seen the action as feasible all along. Feasibility, in other words, is better thought of as tracking the dimension of difficulty.

By the same token, the proposal above suggests that it is no more feasible for me to do something I am hugely motivated to do (kiss my baby daughter) than something I would hate to attempt (kiss a frog). But to think otherwise is to confuse feasibility with enthusiasm. It may also mean getting on a slippery slope at the bottom of which is the judgement we want to avoid that if I am entirely unenthusiastic (and so it feels mega hard or even impossible) to dance like a chicken then it is not feasible for me to do so. The final slide would be natural if degrees of feasibility tracked degrees of willingness and could be avoided only by an ad hoc stipulation that complete unwillingness does not mean infeasibility.

Consider next the objection that Proposal 4 (like Proposal 3 before it) underestimates feasible action. I think the following objection has force and should lead us to revise the Proposal. Suppose the agent responds to the same incentive in the same context - for reasons outside her control only some of the time. Suppose, for example, in nine out of ten cases the incentive of $£ 1,000$ reward makes her do an extra hour's work but in one out of ten cases, it does not. Assume away all other incentives and it seems that although, given the incentive, the agent is close to $90 \%$ likely to succeed to perform $\Phi$ (since once she tries to do the extra work, she invariably succeeds), $\Phi$ is not feasible for her. This seems counterintuitive. Although, by assumption, in the $10 \%$ of cases the agent is genuinely motivationally unable to $\Phi$, the fact that in $90 \%$ of (identical) cases she is, seems to suggest she in fact has a (bit faulty) more general ability to try to $\Phi$. If so, we can simplify Proposal 4 as follows: 
Proposal 5: Action $\Phi$ is feasible if there is an incentive I - or had the agent X not seen $\Phi$ as wrong there would be I - such that, given I, X will likely do $\Phi$.

Proposal 5, however, only captures the binary case of whether an action is feasible or not. For the scalar case, though, the notation needs to remain more complicated to avoid the suggestion that the enthusiasm with which an agent responds to an incentive could affect the feasibility of the action. Let the sign * by the Proposal's number denote that it is about scalar feasibility. Proposal 5* disambiguates whether the likelihood of doing $\Phi$ tracks greater likelihood of responding to an incentive or greater likelihood of successful $\Phi$-ing following a response to the incentive.

Proposal 5*: Action $\Phi$ is (more) feasible if there is an incentive $\mathrm{I}-$ or had the agent $\mathrm{X}$ not seen $\Phi$ as wrong there would be I - such that, given I, X will try to $\Phi$ and, given I, X is (more) likely to $\Phi$.

All in all, an account of feasibility should discount the lack of motivation in agents who merely opt not to follow a certain course of action: their lack of motivation does not render the action unfeasible. But it should not discount the lack of motivation in agents who suffer from genuine motivational inability. For this reason we should prefer the account of feasibility that constrains feasibility by responsiveness to incentives to the conditional account. The constrained account preserves the spirit of the conditional account while abandoning the implausible assumption that whether is it motivationally possible for someone to try to do something makes no difference to whether it is feasible for them to do it.

\section{The feasibility of collective action}

Part of the reason why the joint collective action of everyone in the world (who has the capacity to) touch his or her nose seems so utterly unfeasible is that we are dealing with a collective action where there is no method of deciding, communicating and coordinating together: there is no collective agency of any sort. ${ }^{25}$ So while, conditional on everyone trying, the action would be 
carried out, there is no realistic account to hand of what would be involved in having everyone try to touch his or her nose next Tuesday.

And, just to be clear, the difficulty here does not reside merely in a confusion about the question we are asking. We can, of course, be interested in two issues. First, is it feasible for everyone to touch his or her nose next Tuesday? Second, is it feasible for me (or someone else) to get everyone to touch his or her nose next Tuesday? Clearly, the second action is not feasible for me (or anyone else) and the conditional account does not imply that it is. ${ }^{26}$ The first set of actions is not feasible either, however, even though the conditional account suggests it is. The difficulty is also not merely that next Tuesday is just round the corner but that the touching of the noses by all needs to happen on the same day but, by assumption, we are not in the presence of a collective agent here whose parts (the individuals involved) can come and work together.

By contrast, in typical single-agent cases that the 'conditional on trying' clause is meant to solve the chicken dance - we know what is involved in the agent trying to perform the action: the agent just has to decide to dance like a chicken. ${ }^{27}$ There remains a mystery, of course, as the section above illustrates, of what exactly takes place when a person decides. There is also the mystery of what exactly takes place when a coordinated group, such as a football team or a University, decide: how does the coordination happen? But the scale of the mystery is of a different magnitude than in the mass nose touching case. For 3 billion people to simultaneously touch their noses we need either massive coordination - but, if so, then we are no longer in the realm of merely joint collective action - or we need magic. An account of feasibility should not classify as feasible actions whose performance depends on magic.

Given that the problem with (some) joint collective action and uncoordinated collective action is the mystery of what trying to perform the action would amount to for the individuals involved since they themselves are in the dark, we should obviously refine our understanding of feasibility 
to take care of that. In fact, if we go back to the case of individual action, we notice that knowledge of how to do $\Phi$ is essential for the feasibility of $\Phi$. By knowing 'how to do $\Phi$ ' I mean two things. First, a person needs to know that the action, if successful, will attain a state of affairs S (operating will save a life rather than be part of a horrific art project). This is the case since, given my definition of action $\Phi$ above, actions are in part defined by the state of affairs they attain. An agent who does not know that pressing a stone (which she would never dream of touching otherwise) will open a secret escape passage does not know that she can escape and escaping is not feasible for her. Second, the person needs to know how to do whatever $\Phi$ involves (grafting a healthy artery to a coronary artery rather than just poking around in the human body to save a life; pressing the stone to open the passage). Here 'knowing how to' is also meant to include cases where, say, a tennis player knows how to score an ace even if she does not know precisely how to arrange her body; her body arranges itself so to speak.

Of course, knowledge is only in part a function of cognitive ability and access to sources, it also depends on motivation. Thus one has the ability to know how to spell 'knowledge' in Polish even if one purposefully sticks fingers in ones' ears to avoid hearing the letters in 'wiedza'. That said, knowledge is, of course, also dependent on access to sources of knowledge. Thus even the smartest and most motivated monolingual speaker of English on a desert island with no books and internet has no ability to know how to spell it. In line with the analysis of motivational ability in the previous section, we can say that one has the ability to know $\mathrm{K}$ if there is an incentive I (or would be such an incentive had the agent not seen seeking or obtaining such knowledge as wrong) such that, given I, she will know K. And, since doing $\Phi$ is not possible without knowing how to do $\Phi$ (or, in case of collective action, that $\Phi_{\mathrm{n}}$ is needed), it would appear we can just cut out any reference to knowledge in our definition of feasibility and rely simply on the thought (roughly put here) that an action is feasible if there is an incentive I such that given I, the agent will likely do $\Phi$. 
Things are more complicated, however. The Proposal - as it is stated so far - is most naturally interpreted as presupposing that either an incentive has been offered to the agent to perform the action, thus rendering the action thinkable for the agent, or that the agent is in fact already attempting to perform the action and so, again, the action is thinkable for her. (An analogous problem appears for the conditional account since the account asks what happens if the agent is trying to perform the action, thus the agent is presumed to have knowledge of what doing it involves.) But a correct assessment of the feasibility of $\Phi$ for agent $\mathrm{X}$ should take into account whether $\mathrm{X}$ is in position in context $\mathrm{C}$ at time $\mathrm{T}$ to actually know what $\Phi$ involves (i.e. know that successful $\Phi$-ing will result in S and how to $\Phi){ }^{28}$ Given this, we should revise the Proposal as follows. I refer to it as the constrained account of feasibility since feasibility here is seen as constrained by agents’ responsiveness to incentives and their knowledge:

Proposal 6: Action $\Phi$ is feasible if there is an incentive I - or had the agent $\mathrm{X}$ not seen $\Phi$ as wrong there would be I - such that, given I, X will likely do $\Phi$, and agents' knowledge how to do $\Phi$ is not contained in the offer of this incentive.

Proposal 6*: Action $\Phi$ is (more) feasible if there is an incentive I - or had the agent $\mathrm{X}$ not seen $\Phi$ as wrong there would be I - such that, given I, X will try to $\Phi$ and, given I, X is (more) likely to $\Phi$, and agents' knowledge how to do $\Phi$ is not contained in the offer of this incentive. $^{29}$

Next, let me make the fact that the agent can be collective explicit in the Proposal. Once we do this, we can soften the final condition to reflect the fact that not each individual involved in the collective action needs to see the whole picture. That is, some instances of collective action are possible without all those involved being aware of how or even that they contribute to $\Phi$; all the individual agents may need to know is that she needs to do $\Phi_{n}$ (i.e. that her doing $\Phi_{n}$ is called for for whatever reason: because it will contribute to $\Phi$, or because someone has ordered you to do it, 
etc.). Also note that in the case of collective action by 'an incentive I' I mean 'a set of incentives such that there is an incentive for each agent whose actions constitute the collective action.'

Proposal 7 (collective action): Action $\Phi$ is feasible if there is an incentive I - or had $X_{1 . . .} X_{n}$ not seen doing $\Phi_{1} \ldots \Phi_{\mathrm{n}}$ as wrong there would be I - such that, given I, all agents $\mathrm{X}_{1} \ldots \mathrm{X}_{\mathrm{n}}$ whose individual actions $\Phi_{1} \ldots \Phi_{\mathrm{n}}$ constitute action $\Phi$ are likely ${ }^{30}$ to do $\Phi_{1} \ldots \Phi_{\mathrm{n}}$, and if each $\mathrm{X}_{1} \ldots \mathrm{X}_{\mathrm{n}}$ 's knowledge of how to do $\Phi$, or that $\Phi_{\mathrm{n}}$ is needed is not contained in the offer of this incentive.

Proposal 7* (collective action): Action $\Phi$ is (more) feasible if there is an incentive I - or had $\mathrm{X}_{1 \ldots} \mathrm{X}_{\mathrm{n}}$ not seen doing $\Phi_{1} \ldots \Phi_{\mathrm{n}}$ as wrong there would be I - such that, given I, all agents $\mathrm{X}_{1} \ldots \mathrm{X}_{\mathrm{n}}$ whose individual actions $\Phi_{1} \ldots \Phi_{\mathrm{n}}$ constitute action $\Phi$ are likely to try to do $\Phi_{1} \ldots \Phi_{\mathrm{n}}$ and are (more) likely to do $\Phi_{1} \ldots \Phi_{\mathrm{n}}$, and if each $\mathrm{X}_{1} \ldots \mathrm{X}_{\mathrm{n}}$ 's knowledge of how to do $\Phi$ or that $\Phi_{\mathrm{n}}$ is needed is not contained in the offer of this incentive.

On this account, an action of 3 billion people touching his or her noses next Tuesday is correctly classified as unfeasible because there aren't 3 billion people who could know next Tuesday how to do it or that their individual contributions are needed. (Of course it remains open that this may become possible in future, in which case the action will become feasible then.) But the account also allows us to make sense of the intuition that sometimes even joint or uncoordinated collective action is feasible. For example, it is possible that everyone who needs to be involved has the ability to know what it would take to eliminate child prostitution (e.g. the customers would need to stop seeking it, children would need anonymous access to child protection services without triggering deportation, etc.). It is also possible that each person knows what he himself needs to do and that he needs to do it (e.g. one law enforcement official may need to know how to talk to a child given how others have treated the child, but she need not know, say, what her colleague 
needs to say to the child's client). If so, eliminating child prostitution seems feasible (if extremely unlikely, given the actual motivations of some of those involved).

But the constrained account may be subject to an objection that it rules out too many collective actions as unfeasible. This objection is best introduced with the help of the following hypothetical scenario constructed by Estlund:

'Slice and Patch go golfing. Suppose that unless the patient is cut and stitched he will worsen and die (though not painfully). Surgery and stitching would save his life. If there is surgery without stitching, the death will be agonizing...Slice and Patch are each going golfing whether the other attends to the patient or not. Does anyone act wrongly? Patch ought to stitch the patient if and only if Slice will be doing the surgery (stitching is possible, but pointless and harmful if there is no wound that needs stitching). But suppose that Slice will not be doing the surgery. Patch might as well go golfing. Ought Slice to cut? Well, no, because Patch will not be there to stitch, and so the surgery will only make the patient's death more painful. Slice might as well go golfing. Neither has acted (or omitted) wrongly, despite the fact that the patient will needlessly die. ${ }^{31}$

Estlund is interested here not in the feasibility of their actions but in whether Slice and Patch fail by any moral requirement, but the scenario illuminates how we should think about feasibility (and, in fact, I think that we can gain purchase on the issue of moral requirements in this instance by considering the issue of feasibility). Estlund wonders whether there has been any moral failure, where for moral failure of a collective action to arise (he assumes and I agree) it must be the case that we can point to individuals who act wrongly. Estlund leaves the question of whether there actually is moral failure open, but he does assert that: 'Many of us respond to this case with the intuition that there is some moral violation here...' and he talks of 'the common response of moral offense or outrage when the patient is left to die'. If we accept these intuitions, the puzzle, he 
points out, is 'to find an agent who has committed it so that we can close the 'normativity gap' between the intuition of the presence of some moral violation and the difficulty to pin pointing how any individual involved violates any moral obligations. ${ }^{32}$ Ultimately, Estlund identifies an inconsistent triad of beliefs, at least one of which must be given up: 1. 'Moral failure: It is morally wrong if the patient is left to die.' 2. 'No wrong without obligation: 'If something is morally wrong, then there was an obligation on some agent to act or omit other than as they did.' 3 . 'No violating agent: There is no agent in this case who is morally required to act (or omit) otherwise. $^{33}$

As it happens, I think that we should discard the first of these beliefs, but my reason for reporting the example is not to fight that battle, but to consider the following question: Are Slice and Patch being asked to do something feasible? The answer may appear obvious: surely it is feasible for them to operate (and, consequently, to save the life). But I do not think the answer is so obvious. Here is why. I assume that each agent in question has a good reason to believe that the other will be absent from the operating table or, more weakly, no good reason to suppose that she should make herself available. Otherwise, if Slice had a reason to believe that Patch will be there, or a means of bringing Patch there, then she should not, relative to her evidence, go golfing: She would violate a moral obligation even if it turned out that Patch did go golfing. So we should assume that neither agent can communicate with the other about the other's plans and each has a good reason to believe that the other will be absent. But if this is the case, then it is not clear that saving the patient is a feasible moral requirement. Of course, normally doctors can reasonably grasp what each needs to do to operate and save a life but in this specific instance this is not the case. So the requirement to operate and save a life is not feasible in light of my proposed account.

Given this, Slice and Patch are being asked to do what is not feasible for each to do. We should therefore also reject the description of the case in which 'the patient is left to die' if being 'left to die' is meant to refer to an action performed by a conscious agent as opposed to it being a state of the world. After all, since Slice has no reason to believe Patch will be there, he is not leaving the 
patient to die and nor is Patch. Hence no one is leaving the patient to die. They would have left the patient to die if they were able to communicate and coordinate, but they cannot. We could hang on to our sense that they together leave the patient to die if we rejected the (correct) assumption made by Estlund that for a group to fail it must be the case that individual members of the group fail. ${ }^{34}$ Since we should not do that, we should give up on the belief that there is a moral failure here that goes beyond the possible failure by the protagonists to respond with the right attitudes to the situation. We can still condemn each of them, that is, if they delight in, or hope for, or even simply do not regret the situation that arises. But this is a condemnation of something other than whether they meet a normative requirement to operate.

The conclusion that saving the life of the patient is not feasible might be thought as a reductio of the constrained account of feasibility. But to see the intuition driving my conclusions, consider a different case. Suppose there are two individuals, each located in a separate room equipped with a row of 1,000 consecutively numbered buttons. To save a life of a third person, each agent must press the button of the same number as the other agent. And suppose they cannot communicate with each other. If so, the requirement that they save the life would, I take it, not strike us as feasible. It is certainly possible for them to save the life if, by accident, they press the right buttons, but it is no more feasible for each to press that button than it is for someone without any medical knowledge to perform open heart surgery. In neither case can the agents know what is required to pull off the action successfully.

Granted, as we reduce the number of buttons, the intuition that the requirement to save the life is not feasible appears weaker and weaker. But this is because we accept that some element of luck is compatible with an action being feasible; otherwise almost no action would qualify as such. So we think it is feasible to make a phonecall, even though one's phone could give up and we think it is feasible to drive to a shop even though one could be in an accident. I do not know how little or much control an agent needs to have for us to deem an action as feasible. If it is as little as $50 \%$, that could explain why we may nonetheless think that the action of saving a life in the two button 
case remains feasible. But the fact that we allow judgments of feasibility to depend on the likelihood of success does not mean that we should discard the intuition that it must be the likelihood of success of an action - where there is an agent who is acting - rather than states of the world coming together to produce an outcome with no appropriate agency involvement. This is why we can say that it is feasible for me to walk on a tight rope if I have the skill to do it, but we should not say it is feasible for me if I can only do it when you hypnotise me and I cannot get you to hypnotise me (where I understand hypnosis in the psychologically inaccurate but philosophically familiar sense of something that overrides the agent's will replacing it with that of the hypnotiser). In the latter case, it is perhaps feasible for you to make me walk on a tightrope but walking on a tightrope is not feasible for me.

The feasibility of actions depends on there being an intentional agent, single or collective, who can perform the action in question. Thus going back, as advertised, to the earlier example of open heart surgery, the reason why it is not feasible for me to perform it (even though it is possible that I might succeed if I am extraordinarily lucky) is that I have no idea what such an action would involve. An account of feasibility should not collapse feasibility into possibility even at the extremes of the continuum of feasible action. The constrained account avoids doing so. ${ }^{35}$ Of course, this still leaves unanswered the big question of what counts as an action performed by an intentional agent rather than a mere bodily movement, but I think we can begin to use the account of feasibility here proposed while relying on an imprecise understanding of agency. Or, to put the point more positively, the account of feasibility should work with a number of different accounts of agency that could be plugged into it.

All in all, we should adopt the following constrained account of feasible action, as outlined above: ${ }^{36}$

Definitions: 
[a.] 'Action $\Phi$ is feasible' means 'Action $\Phi$ is feasible for agent $X$ '

[b.] 'Action $\Phi$ ' means either 'action $\Phi$ done by an individual' or 'collective action $\Phi$ constituted by $\Phi_{1} \ldots \Phi_{\mathrm{n}}$ done by $\mathrm{X}_{1} \ldots \mathrm{X}_{\mathrm{n}}$

[c.] 'Agents $X_{1} \ldots X_{n}$ do $\Phi_{1} \ldots \Phi_{n}$ ', means 'each agent $X_{1} \ldots X_{n}$ respectively does $\Phi_{1} \ldots \Phi_{n}$ '

[d.] 'Agent X' means either 'an individual agent' or 'a collective agent composed of all those individuals $\mathrm{X}_{1} \ldots \mathrm{X}_{\mathrm{n}}$ whose each respective doing of $\Phi_{1} \ldots \Phi_{\mathrm{n}}$ constitutes the collective action $\Phi$ '.

[e.] 'Agent $\mathrm{X}$ does $\Phi$ ' means 'in context $\mathrm{C}$ at time $\mathrm{T}$, agent $\mathrm{X}$ succeeds in performing action $\Phi$ thereby bringing about state of affairs S'.

[f.] 'Knowing' means 'knowing in context $\mathrm{C}$ at time $\mathrm{T}$ when the action $\Phi$ is performed'.

[g.] 'Knowing how to do $\Phi$ ' means 'knowing that succeeding in doing $\Phi$ results in $\mathrm{S}$ and how to $\Phi$ '.

[h.] 'Trying to do $\Phi$ ' means 'engaging in an appropriately sustained attempt to do $\Phi$ so that any failure to do $\Phi$ is not due to the agent giving up too early'. ${ }^{37}$

[i.] In case of collective action 'an incentive I' means 'a set of incentives such that there is an incentive for each agent whose actions constitute the collective action'.

The constrained account of feasibility: individual action. Action $\Phi$ is (more) feasible iff there is an incentive I (or had the agent X not seen doing $\Phi$ as wrong there would be I), such that, given I,

[1.] agent $\mathrm{X}$ is likely to try to do $\Phi$

and

[2.] agent $\mathrm{X}$ is (more) likely to do $\Phi$

and

[3.] agent X's knowledge of how to do $\Phi$ is not contained in the offer of this I. 
The constrained account of feasibility: collective action. Action $\Phi$ is (more) feasible iff there is a an incentive I (or had the agents $\mathrm{X}_{1 \ldots} \mathrm{X}_{\mathrm{n}}$ not seen doing $\Phi_{1} \ldots \Phi_{\mathrm{n}}$ as wrong there would be I), such that, given I,

[1.] agents $X_{1} \ldots X_{n}$ are likely to try to do $\Phi_{1} \ldots \Phi_{n}$

and

[2.] agents $\mathrm{X}_{1} \ldots \mathrm{X}_{\mathrm{n}}$ are (more) likely to do $\Phi_{1} \ldots \Phi_{\mathrm{n}}$

and

[3.] agents $X_{1} \ldots X_{n}$ 's knowledge of how to do $\Phi$, or that his or her $\Phi_{n}$ is needed is not contained in the offer of this I.

Our account of feasibility of individual and collective action should be constrained to take account of agent's responsiveness to incentives and their ability to know how to pull off the action in question. The constrained account preserves the spirit of the conditional account in that it does not get people off the hook with regard to whether their acting is feasible merely if they are unwilling to so act. But it also avoids the pitfalls the conditional account faces when it incorrectly discounts the difficulties that arise due to genuine motivational inability and due to the fact that the collective agent who would need to do the action is unable to act together.

\footnotetext{
${ }^{1}$ I am grateful to Geoffrey Brennan, Kimberley Brownlee, Simon Caney, Brian Carey, Matthew Clayton, Alan Hamlin, Ben Jackson, Jonathan Quong and Adam Swift as well as attendees of a MANCEPT workshop in honour of Alan Hamlin (May 2014) for comments and advice. Simon Caney, Matthew Clayton and Jonathan Quong deserve extra mention for detailed written comments delivered at short notice. I am also grateful to David Schmidtz and George Rudebusch for their comments as referees: they were models of constructive criticism and supererogatory in their helpfulness.

${ }^{2}$ The conditional account is not the only account out there. See for example Alan Hamlin, "Political Feasibility,” e-IR 29 August 2012, http://www.e-ir.info/2012/08/29/political-feasibility/ [accessed 1 November 2015] and David Wiens “Political Ideals and the Feasibility Frontier,” Economics and
} 
Philosophy 31, (2015): 447-477. I focus on the conditional account since I plan to preserve its spirit even if not the letter.

${ }^{3}$ For discussion see Geoffrey Brennan and Nicholas Southwood, "Feasibility in Action and Attitude,” in Toni Rønnow-Rasmussen et al, eds., Hommage á Wlodek: Philosophical Papers Dedicated to Wlodek Rabinowicz, (http://www.fil.lu.se/hommageawlodek/site/papper/Brennan\&Southwood.pdf, 2007) [accessed 1 May 2014] and David Wiens, “'Going Evaluative’ to Save Justice From Feasibility — A Pyrrhic Victory,” The Philosophical Quarterly 64, (2014): 301-307. See also G. A. Cohen, Rescuing Justice and Equality (Cambridge MA: Harvard University Press, 2008) and Anca Gheaus, “The Feasibility Constraint on the Concept of Justice," The Philosophical Quarterly 63, (2013): 445-464 for reasons to reject that 'ought' implies 'is feasible'. Those who believe in genuine moral dilemmas also have a reason to reject it.

${ }^{4}$ My focus throughout will be on the feasibility of actions.

${ }^{5}$ David Estlund, Democratic Authority (Princeton NJ: Princeton University Press, 2008), 13-14.

${ }^{6}$ Pablo Gilabert and Holly Lawford-Smith, “Political Feasibility: A Conceptual Exploration,” Political Studies 60, (2012): 809-825.

${ }^{7}$ Brennan and Southwood, "Feasibility in Action and Attitude”.

${ }^{8}$ Ibid., 10.

${ }^{9}$ Gilabert and Lawford-Smith, "Political Feasibility ...,” 815.

${ }^{10}$ In this I follow David Wiens, "Motivational Limitations on the Demands of Justice," European Journal of Political Theory (forthcoming).

${ }^{11}$ Or perhaps 'and more easily possible'.

${ }^{12}$ In addition to Gilabert and Lawford-Smith, "Political Feasibility ...,” Alan Hamlin, “Political Feasibility," suggests that this is one meaning of feasibility.

${ }^{13}$ Brennan and Southwood, "Feasibility in Action and Attitude," 8-10. Others are sceptical too: cf. David Wiens's ‘restricted possibility account' in his "Political Ideals and the Feasibility Frontier," Economics and Philosophy 31, (2015): 447-477.

${ }^{14}$ I leave it open whether everyone in the relevant collection of people must join or merely a sufficient number of them since I am not here trying to establish what any given individual is required to do. Similarly my definition of collective action above is agnostic about who are the individuals who join in or must join in. 
${ }^{15}$ It could be objected that the conditional account makes no such suggestion since 'the agent' in that account must be understood as everyone who is required to act but since everyone who is required to act in this example cannot be called 'an agent' (it's merely a collection of individuals) then there is no agent who would succeed on trying. Notice, however, that we could simply re-characterise the proposed action as one to be performed by agent 1 and agent $2 \ldots$ and agent 3 billion and, if so, its success would be extremely likely conditional on them each trying to touch their noses next Tuesday.

${ }^{16}$ At this point some might worry, of course, whether 'mere unwillingness' is an impossibility or even a category mistake. For example, some worry that if determinism is true then there is no such thing as simple unwillingness; unwillingness always signals motivational inability since the unwilling agent cannot choose otherwise than she does. I follow Wallace and others in thinking that determinism need not preclude the agent having the ability to do something else than she does, but I hope to put the issue of determinism to one side here. See R. Jay Wallace, Responsibility and the Moral Sentiments (Cambridge MA: Harvard University Press, 1994). As it happens, I am not that troubled by it in any case since I argued elsewhere that in key normative contexts (punishment, blame, liability) we should treat actions that are under mere deterministic guidance control as if they were under our ultimate control. See Zofia Stemplowska, "Holding People Responsible for What They Do Not Control”, Politics, Philosophy \& Economics 7, (2008): 355-77 and “Harmful Choices,” Journal of Moral Philosophy 10, (2013): 488-507.

${ }^{17}$ It might be that a person simply succumbs to sleep while fully motivated not to but my hunch (informed by first-hand experience) is that the ability to motivate oneself to stake awake sometimes goes before sleep arrives.

${ }^{18}$ Gilabert and Lawford-Smith, "Political Feasibility ...,” 818.

${ }^{19}$ At this point it might be tempting to try to side-step the whole problem of identifying distinct types of motivational failure by appealing to a different rationale for the view that motivational failure alone does not signal the inability to perform the action. Thus David Estlund, "Human Nature and the Limits (If Any) of Political Philosophy,” Philosophy \& Public Affairs 39, (2011): 207-237 has proposed (in the context of a debate about moral requirements) that even genuine motivational inability does not block the agent's ability to perform the action. In other words, even agents who genuinely cannot achieve the right motivational state to undertake action A could have the ability to perform action $\Phi$. However, I do not share the intuition that 
the question of whether someone has the ability to do $\Phi$ can be settled without interrogating the exact nature of their motivational failure.

${ }^{20}$ David Wiens, "Motivational Limitations on the Demands of Justice," European Journal of Political Theory (forthcoming).

${ }^{21}$ In future we may also have a brain account - are the synapses firing the right way but we are not (yet?) able to identify a one to one correspondence between brain activity and motivational states.

${ }^{22}$ Since this is a counterfactual condition there is a possibility of sequencing such that the agent both renders herself insensitive to all incentives but also no longer sees the action as wrong. I would bite the bullet here and accept that the action is in such cases no longer feasible for the agent. The introduction of the counterfactual clause also raises the question of why not drop the clause altogether and make feasibility a function of the normative desirability of action such that if an action is seen by the agent as so wrong that there is no I to which she would respond, the action should be seen as not feasible for her. There are three key advantages of avoiding such a move, however: first, as mentioned above, the lack of motivation to pursue an action out of normative convictions expresses our agency rather than limits it. Second, sometimes people may do what they find morally unthinkable by accident or in a fit of passion and an account of feasible action that decouples feasibility from desirability makes it easier to explain such situations: the action was feasible after all. Third, such an account makes it easier to attribute appropriate moral praise to people who abstain from doing what is undesirable: the action was feasible but they chose to avoid it. ${ }^{23}$ Does the proposal give the right answer in the case of someone who fails to respond to incentives to not $\Phi$ because $\Phi$-ing there and then is the sole thing she wholeheartedly ever wants to do or have come about? Although the person does not respond to incentives, not desisting from $\Phi$ seems to be due to her mere unwillingness rather than genuine motivational inability and the action to desist seems feasible for her. Such people are hard to imagine: it's not enough to think here of someone whose sole wish is to climb Mount Everest under the exact conditions of her current life - we must assume that she would rather do that than see any other state of affairs come about. I am prepared to bite the bullet that in cases of such unique single mindedness, it is in fact not feasible for the person to desist from $\Phi$-ing.

${ }^{24}$ G. A. Cohen, “On the Currency of Egalitarian Justice,” Ethics 99, (1989): 906-944, 918-919.

${ }^{25}$ I assume that there also isn't here a singular agency, such as a dictator, who can simply use the individuals involved. 
${ }^{26}$ See Gilabert and Lawford-Smith, "Political Feasibility ...," 818.

${ }^{27}$ I am not saying that deciding to do $\Phi$ is the only way to engage agency in the doing of $\Phi$, but it is one way of engaging it.

${ }^{28}$ She may, of course, be in position precisely because an incentive has been offered to her to do $\Phi$ but this cannot be assumed since it is not generally true of all feasible actions. If the agent's knowledge comes from an incentive it must be a separate incentive that has actually been offered to (or encountered by) the agent.

${ }^{29}$ Strictly speaking, the Proposal could continue along the lines of 'unless the I is actually offered to the agent by time $\mathrm{T}$ rather than merely hypothesised' but we can side-step this complication.

${ }^{30}$ Where we can use the standard mathematical formula for calculating combined probability of joint action: i.e. it is enough that the doing of $\Phi_{1} \ldots \Phi_{\mathrm{n}}$ in concert by the agents is likely rather than that each individual $\Phi_{\mathrm{n}}$ is likely.

${ }^{31}$ David Estlund, “Prime Justice,” in Kevin Vallier and Michael Weber, eds., Political Utopias (Oxford: Oxford University Press, forthcoming).

${ }^{32}$ He adds: 'The intuition that something goes morally wrong here cannot be handled by saying it is a matter of conditional obligations: each should act so long as the other does. The antecedent is not met, so no such conditional obligation has been violated either.' Estlund, ibid.

${ }^{33}$ Ibid.

${ }^{34}$ But compare Holly Lawford-Smith, “The Feasibility of Collectives’ Action,” Australian Journal of Philosophy 90, (2012): 453-467.

${ }^{35}$ Strictly speaking, then, we could say that feasibility is about possibility, but it is about the possibility of action by agents who know how to do what is needed; it is not about a possible confluence of events that make some outcomes possible; it is about acting not about things occurring. Cf. David Wiens's 'Restricted possibility account' in his "Political Ideals and the Feasibility Frontier," 447-477.

${ }^{36}$ I am indebted to George Rudebusch for criticism of my previous formulations.

${ }^{37}$ See endnote 10. 